University of Wollongong

Research Online

Australian Institute for Innovative Materials -

Papers

Australian Institute for Innovative Materials

$1-1-2014$

The synergistic effect between WO3 and g-C3N4 towards efficient visiblelight-driven photocatalytic performance

Imran Aslam

Beijing Institution Of Technology

Chuanbao Cao

Beijing Institute of Technology

M Tanveer

Beijing Institution Of Technology

Waheed S. Khan

Beijing Institute of Technology

Muhammad Nawaz Tahir

Beijing Institute of Technology

See next page for additional authors

Follow this and additional works at: https://ro.uow.edu.au/aiimpapers

Part of the Engineering Commons, and the Physical Sciences and Mathematics Commons

Research Online is the open access institutional repository for the University of Wollongong. For further information contact the UOW Library: research-pubs@uow.edu.au 


\title{
The synergistic effect between WO3 and g-C3N4 towards efficient visible-light- driven photocatalytic performance
}

\begin{abstract}
We have developed a facile, scaled up, efficient and morphology-based novel WO3-g-C3N4 photocatalyst with different mass ratios of WO3 and g-C3N4. It was used for the photodegradation of rhodamine B $(\mathrm{RhB})$ under visible light irradiation and it showed excellent enhanced photocatalytic efficiency as compared to pure g-C3N4 and W03. The apparent performance of the composite/hybrid was 3.65 times greater than pure WO3 and 3.72 times greater than pure g-C3N4 respectively, and it was also found to be much higher than the previously reported ones. Furthermore, the optical properties of composite samples were evaluated. The bandgap of composite samples lies in the range of 2.3-2.5 eV, which was favourable for photodegradation. The possible mechanism for enhanced catalytic efficiency of the WO3-g-C3N4 photocatalyst is discussed in detail. It was found that the enhanced performance is due to the synergistic effect between the WO3 and g-C3N4 interface, improved optical absorption in the visible region and suitable band positions of WO3-g-C3N4 composites. This journal is
\end{abstract}

\section{Keywords}

towards, c3n4, g, wo3, between, effect, synergistic, driven, performance, light, photocatalytic, visible, efficient

Disciplines

Engineering | Physical Sciences and Mathematics

\section{Publication Details}

Aslam, I., Cao, C., Tanveer, M., Khan, W. S., Tahir, M., Abid, M., Idrees, F., Butt, F. K., Ali, Z. \& Mahmood, N. (2014). The synergistic effect between WO3 and g-C3N4 towards efficient visible-light-driven photocatalytic performance. New Journal of Chemistry: a journal for new directions in chemistry, 38 (11), 5462-5469.

\section{Authors}

Imran Aslam, Chuanbao Cao, M Tanveer, Waheed S. Khan, Muhammad Nawaz Tahir, Muhammad Abid, Faryal Idrees, Faheem K. Butt, Zulfiqar Ali, and Nasir Mahmood 


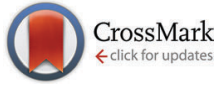

Cite this: New J. Chem., 2014 38,5462

Received (in Montpellier, France) 13th August 2014, Accepted 2nd September 2014

DOI: 10.1039/c4nj01370k

www.rsc.org/njc

\title{
The synergistic effect between $\mathrm{WO}_{3}$ and $\mathrm{g}-\mathrm{C}_{3} \mathrm{~N}_{4}$ towards efficient visible-light-driven photocatalytic performance $\dagger$
}

\author{
Imran Aslam, ${ }^{a}$ Chuanbao Cao, ${ }^{* a}$ Muhammad Tanveer, ${ }^{a}$ Waheed S. Khan, ${ }^{a}$ \\ Muhammad Tahir, ${ }^{a}$ Muhammad Abid, ${ }^{b}$ Faryal Idrees, ${ }^{a}$ Faheem K. Butt, ${ }^{a}$ \\ Zulfiqar Ali $^{\mathrm{a}}$ and Nasir Mahmood ${ }^{\mathrm{C}}$
}

\begin{abstract}
We have developed a facile, scaled up, efficient and morphology-based novel $\mathrm{WO}_{3}-\mathrm{g}-\mathrm{C}_{3} \mathrm{~N}_{4}$ photocatalyst with different mass ratios of $\mathrm{WO}_{3}$ and $\mathrm{g}-\mathrm{C}_{3} \mathrm{~N}_{4}$. It was used for the photodegradation of rhodamine $\mathrm{B}(\mathrm{Rh} B)$ under visible light irradiation and it showed excellent enhanced photocatalytic efficiency as compared to pure $\mathrm{g}-\mathrm{C}_{3} \mathrm{~N}_{4}$ and $\mathrm{WO}_{3}$. The apparent performance of the composite/hybrid was 3.65 times greater than pure $\mathrm{WO}_{3}$ and 3.72 times greater than pure $\mathrm{g}-\mathrm{C}_{3} \mathrm{~N}_{4}$ respectively, and it was also found to be much higher than the previously reported ones. Furthermore, the optical properties of composite samples were evaluated. The bandgap of composite samples lies in the range of 2.3-2.5 eV, which was favourable for photodegradation. The possible mechanism for enhanced catalytic efficiency of the $\mathrm{WO}_{3}-\mathrm{g}-\mathrm{C}_{3} \mathrm{~N}_{4}$ photocatalyst is discussed in detail. It was found that the enhanced performance is due to the synergistic effect between the $\mathrm{WO}_{3}$ and $\mathrm{g}-\mathrm{C}_{3} \mathrm{~N}_{4}$ interface, improved optical absorption in the visible region and suitable band positions of $\mathrm{WO}_{3}-\mathrm{g}-\mathrm{C}_{3} \mathrm{~N}_{4}$ composites.
\end{abstract}

\section{Introduction}

The fabrication of semiconductor photocatalysts with high performance for pollutant degradation has become an attractive topic for researchers nowadays. The visible-light-driven photocatalysts have received great attention in this regard. ${ }^{1-3}$ After the report of Fujishima and Honda, ${ }^{4} \mathrm{TiO}_{2}$ became the most widely used semiconductor photocatalyst ${ }^{5,6}$ due to its low price, non-toxicity and good performance. However, low solar energy conversion efficiency due to a wide band gap $(3.2 \mathrm{eV})$ and a high recombination rate of photogenerated electron-hole pairs have hampered its industrial applications. ${ }^{7,8}$ Therefore, efforts are still being made to synthesize novel photocatalysts that have strong visible light response and high catalytic efficiency as well.

Tungsten trioxide $\left(\mathrm{WO}_{3}\right)$, a transition metal oxide semiconductor with a band gap of 2.6-2.8 eV, has been introduced as an alternative photocatalyst with a lot of potential applications

\footnotetext{
${ }^{a}$ Research Center of Materials Science, Beijing Institute of Technology, Beijing 100081, P. R. China. E-mail: cbcao@bit.edu.cn

${ }^{b}$ School of Physics, Beijing Institute of Technology, Beijing 100081, P. R. China ${ }^{c}$ Department of Materials Science and Engineering, College of Engineering Peking University, Beijing 100871, P. R. China

$\dagger$ Electronic supplementary information (ESI) available: Introduction of RhB, SEM images with length and diameter measurements, and photodegradation curves of $\mathrm{WO}_{3}-\mathrm{g}-\mathrm{C}_{3} \mathrm{~N}_{4}$ (samples S1, S2, S3, S4, S6 and S7). See DOI: 10.1039/c4nj01370k
}

such as a visible-light-driven photocatalyst and related technological applications. ${ }^{9-13}$ However, it has been observed that under visible light it shows a limited catalytic activity because its conduction band edge lies in a position not favourable for single-electron reduction of $\mathrm{O}_{2}$ which makes it a less efficient photocatalyst for organic degradation. ${ }^{14}$ On the other hand, graphite-like carbon nitride $\left(\mathrm{g}-\mathrm{C}_{3} \mathrm{~N}_{4}\right),{ }^{15-17}$ a metal free and nontoxic material, has emerged as one of the promising candidates for photocatalysis especially after the report of Wang et al. ${ }^{18}$ Although g- $\mathrm{C}_{3} \mathrm{~N}_{4}$ has shown a great potential for catalytic activities, but its small surface area and the high recombination rate of photogenerated electron-hole pairs are the factors that limit its performance. ${ }^{19,20}$ Two-dimensional (2D) nanostructures, analogous to graphene, have acquired remarkable interest due to their extraordinary optoelectronic and mechanical properties. The unique feature of $2 \mathrm{D}$ anisotropy helps to gain new physiochemical properties. It is reported that $\mathrm{g}-\mathrm{C}_{3} \mathrm{~N}_{4}$ nanosheets can have an electronic band structure with band edges straddling the water redox potentials making them a promising catalyst for watersplitting to produce hydrogen under sunlight. ${ }^{21,22} \mathrm{~g}-\mathrm{C}_{3} \mathrm{~N}_{4}$ is a soft polymer and can easily be coated on the surface of others compounds, which may help for the transport of photogenerated charge carriers, and hence can be used as an efficient co-catalyst for semiconductor-based photocatalysts to improve their catalytic activity. ${ }^{23}$ One-dimensional (1D) single crystalline structures are of great importance, as they have the potential ability to 
provide a direct path to photogenerated charges, with reduced grain boundaries resulting in superior charge transport properties. ${ }^{24-26}$ Further, 1D nanostructures can provide a high surface to volume ratio with fewer defects. Recently, the coupling of two kinds of photocatalysts with small band gap has become a novel technique to overcome the problems of traditional photocatalysts. ${ }^{27,28}$ Hybrid/heterostructured materials are considered to be good candidates for photon-to-fuel conversion. They provide excellent charge separation and slow down recombination and high separation of photo-induced electron-hole pairs at the interface between two semiconductors which eventually causes the enhanced catalytic activity. ${ }^{29-32} \mathrm{~A}$ lot of efforts including sizecontrolling, ${ }^{33,34}$ noble-metal-loading, ${ }^{35,36}$ coupling with other semiconductors have been devoted to enhance the photocatalytic activity of $\mathrm{WO}_{3} \cdot{ }^{14,37-40}$ Among these studies, it has been confirmed that $\mathrm{WO}_{3}$ is a good candidate for fabricating semiconductor heterojunctions to achieve higher catalytic efficiency. For example, the semiconductors $\mathrm{Fe}_{2} \mathrm{O}_{3},{ }^{14} \mathrm{TiO}_{2},{ }^{37} \mathrm{CuO},{ }^{38} \mathrm{CuBi}_{2} \mathrm{O}_{4},{ }^{39}$ and $\mathrm{CaFe}_{2} \mathrm{O}_{4}{ }^{40}$ etc., have been coupled with $\mathrm{WO}_{3}$ to make the heterostructured/hybrid photocatalysts and they exhibited catalytic performance under visible light. It has been reported that synthesizing the heterostructures by mixing $\mathrm{C}_{3} \mathrm{~N}_{4}$ with other semiconductors facilitates an easy path to promote the separation of photo-induced charge carriers and provides enhanced activity. ${ }^{41,42}$ So, keeping in mind the importance of 1D nanostructures and the problems related to traditional photocatalysts, we came up with an idea of a synergetic approach to form such a hybrid system. There are only a few reports ${ }^{43-45}$ on $\mathrm{WO}_{3}-\mathrm{C}_{3} \mathrm{~N}_{4}$ composites but not with some specific morphological structure. In these reports, they used powder or irregular shaped materials to make the composite and compared the performance of the prepared composite with powdered/irregular structured $\mathrm{WO}_{3}$ and g- $\mathrm{C}_{3} \mathrm{~N}_{4}$. We fabricated $1 \mathrm{D} \mathrm{WO}_{3}$ microrods and mixed them with $2 \mathrm{D} \mathrm{g}-\mathrm{C}_{3} \mathrm{~N}_{4}$ sheets to gain the advantage of such geometry. This

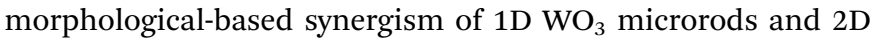
g- $\mathrm{C}_{3} \mathrm{~N}_{4}$ sheets may increase the specific surface area and decrease the number of defects. As a result, the enhanced degradation activities were attained. Moreover, in the synergism of $\mathrm{WO}_{3}-$ g- $\mathrm{C}_{3} \mathrm{~N}_{4}$, the former component helps to reduce the recombination rate of electron-hole pairs while the latter one enhances the active sites of the catalyst surface. ${ }^{43,44}$

Herein, we have presented for the first time a morphology-based novel $\mathrm{WO}_{3}-\mathrm{g}-\mathrm{C}_{3} \mathrm{~N}_{4}(1 \mathrm{D} / 2 \mathrm{D})$ synergetic hybrid system fabricated by a simple hydrothermal and annealing method which exhibited superior photocatalytic activity and stability for the degradation of RhB under visible light irradiation. It can be found that after mixing g- $\mathrm{C}_{3} \mathrm{~N}_{4}$ with $\mathrm{WO}_{3}$, the catalytic efficiency and photo stability of the $\mathrm{WO}_{3}$ microrods were substantially improved. The performance (rate constant $0.06912 \mathrm{~min}^{-1}$ or $4.1472 \mathrm{~h}^{-1}$ ) of the present composite $\mathrm{WO}_{3}-\mathrm{g}-\mathrm{C}_{3} \mathrm{~N}_{4}$ was much higher than that of the reported value. ${ }^{43}$ The work provides new possibilities for hybrid geometries of nanostructures to enhance their properties by a synergistic effect. Further, it may provide new insights for the practical application of $\mathrm{WO}_{3}$ in hydrogen production. In the end, a possible mechanism for the enhanced activity of the $\mathrm{WO}_{3}-\mathrm{g}-\mathrm{C}_{3} \mathrm{~N}_{4}$ composite determined from the experimental results is discussed in detail.

\section{Experimental section}

\section{Fabrication of $\mathrm{WO}_{3}-\mathrm{g}-\mathrm{C}_{3} \mathrm{~N}_{4}$}

$\mathrm{WO}_{3}$ microrods were prepared by hydrothermal treatment. Initially $1.0314 \mathrm{~g}$ of $\mathrm{NaWO}_{4} \cdot 2 \mathrm{H}_{2} \mathrm{O}$ and $0.3714 \mathrm{~g}$ of $\mathrm{NaCl}$ were dissolved in $2 \mathrm{~mL}$ of $2 \mathrm{M} \mathrm{HCl}$ solution and stirred for 30 minutes, during stirring $23 \mathrm{~mL}$ of distilled water was added and the resulting light sky blue solution was transferred to an autoclave and heated at $180{ }^{\circ} \mathrm{C}$ for 48 hours. The obtained material was washed three times with distilled water and absolute ethanol respectively. The $\mathrm{g}-\mathrm{C}_{3} \mathrm{~N}_{4}$ powder was prepared according to the literature. ${ }^{46}$ Typically, $5.0 \mathrm{~g}$ of melamine were taken in an alumina crucible. The crucible was covered and heated at $550{ }^{\circ} \mathrm{C}$ in a muffle furnace with a rate of $2{ }^{\circ} \mathrm{C} \min ^{-1}$ for 4 hours.

The $\mathrm{WO}_{3}-\mathrm{g}-\mathrm{C}_{3} \mathrm{~N}_{4}$ composite was synthesized as follows: the specific amounts of $\mathrm{g}-\mathrm{C}_{3} \mathrm{~N}_{4}$ and $\mathrm{WO}_{3}$ were dispersed in $10 \mathrm{~mL}$ of ethanol separately in beakers and sonificated for 1 hour to obtain a well dispersed homogeneous suspension. The $\mathrm{g}-\mathrm{C}_{3} \mathrm{~N}_{4}$ solution was then poured into the $\mathrm{WO}_{3}$ solution and magnetically stirred for 1 hour. The obtained solution was dried at $80{ }^{\circ} \mathrm{C}$ for 12 hours and then annealed at $350{ }^{\circ} \mathrm{C}$ for 4 hours with a rate of $5{ }^{\circ} \mathrm{C}$ per minutes. According to this method, we prepared the following samples with different mass ratios of $\mathrm{WO}_{3}-\mathrm{g}-\mathrm{C}_{3} \mathrm{~N}_{4}$ : $1: 0$ (S1), $0: 1$ (S2), $1: 0.2$ (S3), $1: 0.5$ (S4), $0.2: 1$ (S5), $0.5: 1$ (S6) and $1: 1(\mathrm{~S} 7)$.

\section{Characterization}

The as-synthesized $\mathrm{WO}_{3}-\mathrm{g}-\mathrm{C}_{3} \mathrm{~N}_{4}$ composite phase characterization was done by X-ray diffraction (XRD; Philips X'Pert Pro MPD), using a $\mathrm{Cu} \mathrm{K} \alpha$ radiation source $(\lambda=0.15418 \mathrm{~nm})$ with $2 \theta$ from $10^{\circ}$ to $80^{\circ}$. The morphology and composition of the as-prepared sample were analyzed by field emission scanning electron microscopy (FESEM) and transmission electron microscopy (TEM, H-600-II, and Hitachi) and the chemical composition of the samples was determined by an energy dispersive X-ray (EDX) analysis (Hitachi S-3500). Fourier transform infrared (FTIR) spectra of samples were recorded using a Nicolet Avatar-370 spectrometer at room temperature. The UV-VIS-NIR (Hitachi-4100) spectrophotometer was used to measure the optical absorption spectra and energy band gap and room temperature photoluminescence (PL) spectra were measured with a Hitachi FL-4500 fluorescence spectrometer.

\section{Photocatalytic test}

The photocatalytic properties of the as-synthesized $\mathrm{WO}_{3}-\mathrm{g}-\mathrm{C}_{3} \mathrm{~N}_{4}$ were evaluated by the degradation of $\mathrm{RhB}$ under visible light. A $500 \mathrm{~W}$ Xenon lamp was used as a visible light source. In order to study the concentration of RhB in solution, the UV-VIS-NIR (Hitachi U-4100) spectrophotometer was used. For photocatalytic test, $0.40 \mathrm{~L}$ of $0.01 \mathrm{M} \mathrm{RhB}$ was taken in a glass beaker and $0.05 \mathrm{~g}$ of the sample material was dissolved in this solution. Prior to irradiation, the solution was magnetically stirred in the dark for 30 minutes to achieve the saturated absorption of RhB onto the catalysts and then this solution was exposed to the visible light. At the irradiation time intervals of every 10 minutes, $3 \mathrm{~mL}$ of the suspension were collected and centrifuged to remove 
the photocatalyst particles every time before measuring the absorption spectra. The initial concentration $\left(C_{0}\right)$ was the maximum absorption peak of the RhB which was recorded as $554 \mathrm{~nm}$. Further details about the RhB dye can be found in the ESI. $\dagger$

\section{Results and discussion}

\section{Phase characterization and morphology}

In the present work, we first synthesized $\mathrm{WO}_{3}$ and g- $\mathrm{C}_{3} \mathrm{~N}_{4}$ separately by a hydrothermal and annealing method and then developed a novel hybrid system/composite $\mathrm{WO}_{3}-\mathrm{g}-\mathrm{C}_{3} \mathrm{~N}_{4}$ using a simple physical mixing and annealing method by choosing different mass ratios of $\mathrm{g}-\mathrm{C}_{3} \mathrm{~N}_{4}$ and $\mathrm{WO}_{3}$. Fig. 1(a) shows the XRD pattern of $\mathrm{WO}_{3}$ (S1) microrods; well-defined peaks with specific intensities can be indexed to the hexagonal phase of $\mathrm{WO}_{3}$ (JCPDS Card No. 75-2187 with lattice constants $a=b=7.2980 \AA, c=3.8990 \AA$ and $\alpha=\beta=90^{\circ}, \gamma=120^{\circ}$ ) with the following distinctive peaks at $14.0^{\circ}, 22.83^{\circ}, 28.17^{\circ}$ and $36.57^{\circ}$ corresponding to (100), (001), (200) and (201) planes respectively. Fig. 1(b) shows the XRD pattern of $\mathrm{g}-\mathrm{C}_{3} \mathrm{~N}_{4}(\mathrm{~S} 2)$, there is only one broad peak appearing at $27.1^{\circ}$ corresponding to $\mathrm{g}-(002)$ planes. Fig. $1(\mathrm{c})$ represents the XRD patterns for all the samples of $\mathrm{WO}_{3}-\mathrm{g}-\mathrm{C}_{3} \mathrm{~N}_{4}$ composites (S3-S7) and the highest peak was observed at $28.06^{\circ}$ for all samples, which means that after the introduction of $\mathrm{g}-\mathrm{C}_{3} \mathrm{~N}_{4}$ the main peak of $\mathrm{WO}_{3}$ slightly changed from the original position and appeared with decreased intensities. But surprisingly no any peak of $\mathrm{g}-\mathrm{C}_{3} \mathrm{~N}_{4}$ was observed in the $\mathrm{WO}_{3}-\mathrm{g}-\mathrm{C}_{3} \mathrm{~N}_{4}$ composites at all, which may be due to very low intensity of $\mathrm{g}-\mathrm{C}_{3} \mathrm{~N}_{4}$ compared to $\mathrm{WO}_{3}$. Since the main peak of pure $\mathrm{WO}_{3}$ is more intense than g- $\mathrm{C}_{3} \mathrm{~N}_{4}$, so when it was mixed with $\mathrm{g}-\mathrm{C}_{3} \mathrm{~N}_{4}$ to make the composite, the peak of pure $\mathrm{g}-\mathrm{C}_{3} \mathrm{~N}_{4}$ couldn't appear. Secondly, there is an interesting reason for the absence of the $\mathrm{g}-\mathrm{C}_{3} \mathrm{~N}_{4}$ peak in the composite samples. As the main peak of $\mathrm{g}-\mathrm{C}_{3} \mathrm{~N}_{4}$ centred at $27.1^{\circ}$ lies between the two $\mathrm{WO}_{3}$ peaks positioned at $26.8^{\circ}$ and $28.17^{\circ}$ corresponding to (101) and (200) planes, respectively, it is simply
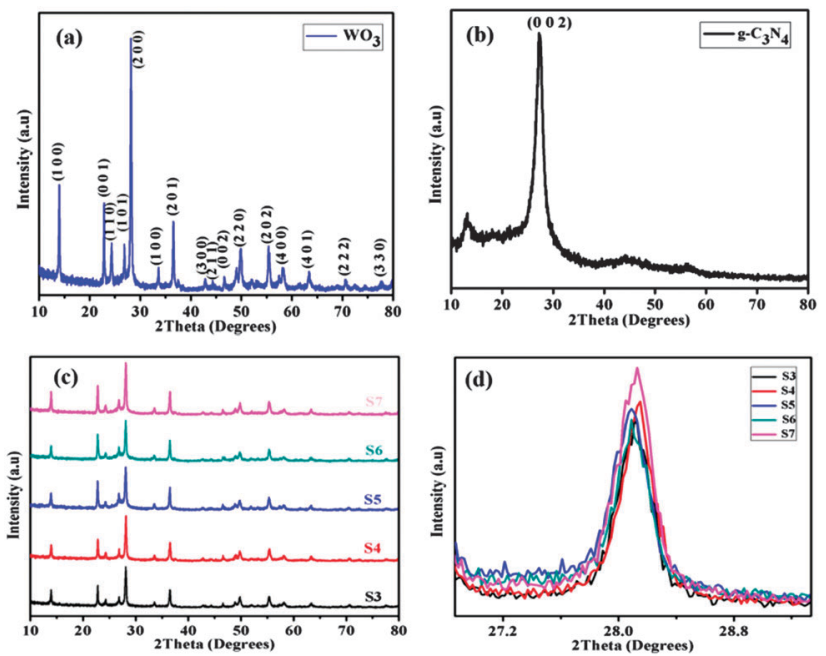

Fig. 1 (a) XRD pattern of $\mathrm{WO}_{3}$ (b) XRD pattern of $\mathrm{g}-\mathrm{C}_{3} \mathrm{~N}_{4}$ (c) XRD patterns of composite samples (S3-S7) (d) XRD patterns of composite samples in a short range.

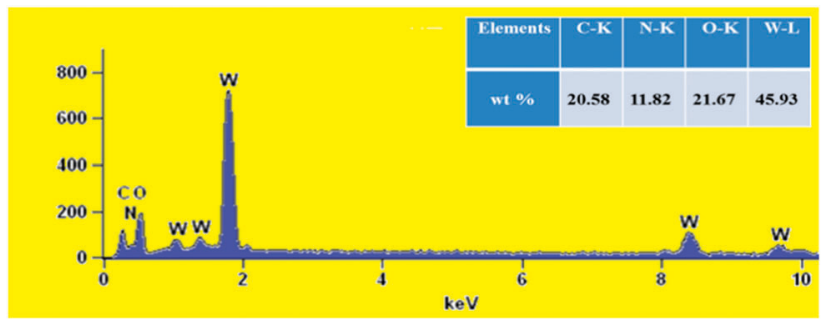

Fig. 2 EDX spectrum of $\mathrm{WO}_{3}-\mathrm{g}-\mathrm{C}_{3} \mathrm{~N}_{4}$ (S5)

impossible for the $\mathrm{g}-\mathrm{C}_{3} \mathrm{~N}_{4}$ peak to appear in the composite samples within a very small $d$-spacing interval. However, the presence of $\mathrm{g}-\mathrm{C}_{3} \mathrm{~N}_{4}$ can be confirmed from Fig. 1(d). It shows a close view of main peaks of all the samples (S3-S7), and one can clearly see that the main peak of $\mathrm{WO}_{3}$ is gradually decreased with the increase of $\mathrm{g}-\mathrm{C}_{3} \mathrm{~N}_{4}$ content. As $\mathrm{g}-\mathrm{C}_{3} \mathrm{~N}_{4}$ has low crystalline nature, the addition of $\mathrm{g}-\mathrm{C}_{3} \mathrm{~N}_{4}$ into $\mathrm{WO}_{3}$ affects the crystallinity of the as-prepared composites and decreases their peak intensity.

Fig. 2 depicts the EDX spectrum of the composite $\mathrm{WO}_{3}-\mathrm{g}-\mathrm{C}_{3} \mathrm{~N}_{4}$ (sample S5) while the inset of Fig. 2 shows elemental composition (wt\%) contained by S5. It can be noticed that the as-synthesized composite is composed of only $\mathrm{C}, \mathrm{N}, \mathrm{O}$ and $\mathrm{W}$ elements which means that the as-prepared sample is pure and no any kind of impurity is present.

The morphologies of the as-prepared materials are shown in Fig. 3. Fig. 3(a) shows the SEM image of pure $\mathrm{WO}_{3}$ rod like structure. It can be observed from the figure that the as-synthesized $\mathrm{WO}_{3}$ rods are very dense and uniform. The diameter of these rods is in the

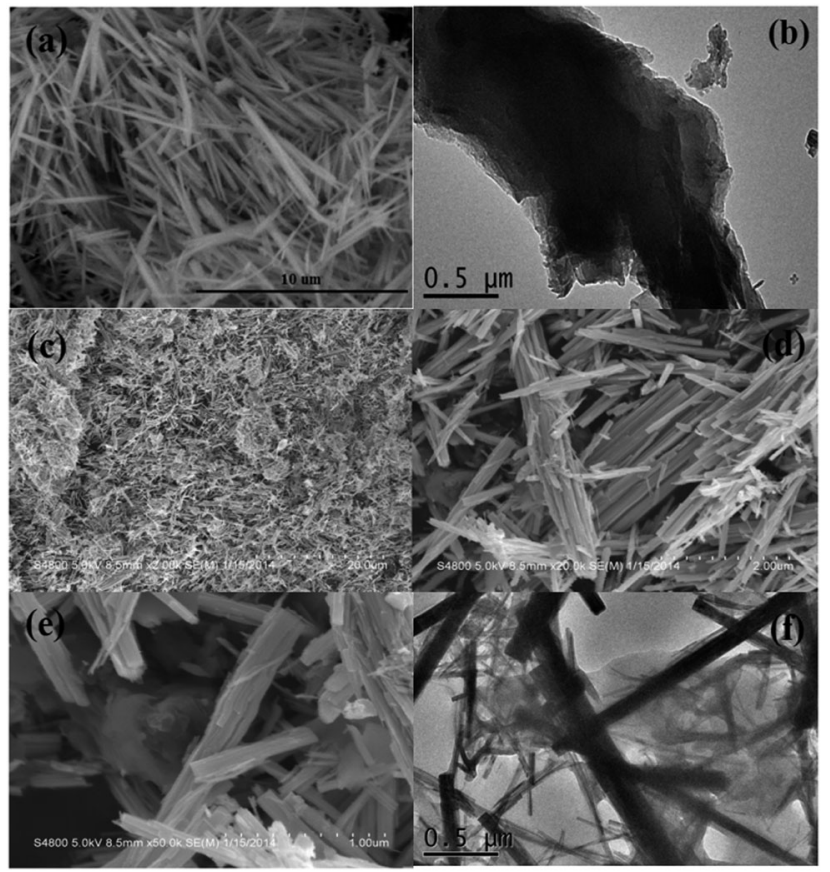

Fig. 3 (a) SEM image of $\mathrm{WO}_{3}$ rods, (b) TEM image of $\mathrm{g}-\mathrm{C}_{3} \mathrm{~N}_{4}$ sheets (c-e) FESEM images of the as-synthesized composite $\mathrm{WO}_{3}-\mathrm{g}-\mathrm{C}_{3} \mathrm{~N}_{4}$ (sample S5) at different magnifications ( $f$ ) TEM image of S5. 
range of $200-300 \mathrm{~nm}$ while the length is in the range of $4-7 \mu \mathrm{m}$ (Fig. S1 ESI $\dagger$ ). Fig. 3(b) shows the TEM image of the sheet like structure of $\mathrm{g}-\mathrm{C}_{3} \mathrm{~N}_{4}$. It can be seen from the figure that these sheets are arranged in layers. Fig. 3(c-e) shows the FESEM images of the fabricated composite $\mathrm{WO}_{3}-\mathrm{g}-\mathrm{C}_{3} \mathrm{~N}_{4}$ at different magnifications. The FESEM images in Fig. 3(c-e) show the combination of rod and sheet like structures of $\mathrm{WO}_{3}-\mathrm{g}-\mathrm{C}_{3} \mathrm{~N}_{4}$. In addition, we can see more clearly the rod and sheet like structure of $\mathrm{WO}_{3}-\mathrm{g}-\mathrm{C}_{3} \mathrm{~N}_{4}$ (S5) from the TEM image in Fig. 3(f).

\section{FTIR analysis}

To further confirm the composition information and chemical bonding present in $\mathrm{WO}_{3}, \mathrm{~g}-\mathrm{C}_{3} \mathrm{~N}_{4}$ and $\mathrm{WO}_{3}-\mathrm{g}-\mathrm{C}_{3} \mathrm{~N}_{4}$ composite samples, the FTIR spectra of all the samples were measured, as indicated in Fig. 4. Fig. 4(a-c) shows the FTIR spectra of all the samples, for $\mathrm{WO}_{3}(\mathrm{~S} 1)$, the absorption band around $820 \mathrm{~cm}^{-1}$ is clearly shown which corresponds to $\mathrm{O}-\mathrm{W}-\mathrm{O}$ stretching vibration in a monoclinic-type $\mathrm{WO}_{3}$ crystal. ${ }^{47}$ For $\mathrm{g}-\mathrm{C}_{3} \mathrm{~N}_{4}(\mathrm{~S} 2)$, the FTIR confirms the presence of two main bonds in the products. The absorption peaks ranging from 800 to $1600 \mathrm{~cm}^{-1}$ are the strong indications of the heterocycles present in $\mathrm{g}-\mathrm{C}_{3} \mathrm{~N}_{4} ;{ }^{48,49}$ these peaks are due to the breathing mode of $s$-triazine, $\mathrm{sp}^{3}$ $\mathrm{C}-\mathrm{N}$ bonds and $\mathrm{sp}^{2} \mathrm{C}=\mathrm{N}$. The peaks because of the stretching vibration modes of $\mathrm{NH}$ and $\mathrm{NH}_{2}$ groups are observed in the range of $2500-3500 \mathrm{~cm}^{-1}$ in $\mathrm{S} 2 .^{50,51}$ In the case of all other samples the intensity of peaks around 820 are not so high which may be due to the presence of $\mathrm{g}-\mathrm{C}_{3} \mathrm{~N}_{4}{ }^{52}$ which can clearly be seen in Fig. 4(b). The peaks observed in the range of $3000-3550 \mathrm{~cm}^{-1}$ may be attributed to the $\mathrm{O}-\mathrm{H}$ stretching vibrations of physically absorbed water ${ }^{53-55}$ and around 1380-1660 $\mathrm{cm}^{-1}$ could correspond to $\mathrm{H}-\mathrm{O}-\mathrm{H}$ bending and $\mathrm{O}-\mathrm{H}$ stretching vibrations of the adsorbed water molecules on the surface. ${ }^{56,57}$

\section{Optical absorption properties}

Further, the UV spectra of $\mathrm{WO}_{3}, \mathrm{~g}-\mathrm{C}_{3} \mathrm{~N}_{4}$ and all the composite samples were examined, as can be seen in Fig. $5(\mathrm{a}-\mathrm{c})$. It can be noted that the absorption band edge for the case of pure $\mathrm{WO}_{3}$ lies at around $400 \mathrm{~nm}$ while for pure $\mathrm{g}-\mathrm{C}_{3} \mathrm{~N}_{4}$ at around $410 \mathrm{~nm}$ as can be seen in Fig. $5(\mathrm{c})$. The introduction of $\mathrm{g}-\mathrm{C}_{3} \mathrm{~N}_{4}$ into $\mathrm{WO}_{3}$ causes the absorption edge shift towards the longer wavelength range and the absorption band edges for composite samples were recorded at around $460 \mathrm{~nm}$ as shown in Fig. 5(c). This shifting of absorption edges resulted in the decrement of band gaps. The decreased band gap of the composite samples can absorb more energy than pure samples which will excite more number of electrons from valence bands to conduction bands. As a result, more number of electron-hole pairs will be produced at the interface between two semiconductors and hence the catalytic performance will be improved. Fig. 5(d) represents band gaps of all the samples as a function of $\mathrm{g}-\mathrm{C}_{3} \mathrm{~N}_{4}$ content. The graph is almost linear in the middle section from 0.16 to 0.66 ; we have thus controlled the band gap within the range of $2.3-2.5 \mathrm{eV}$ by a suitable mass ratio of $\mathrm{g}-\mathrm{C}_{3} \mathrm{~N}_{4}$. Also it is strongly suggested that the band gap of composite of $g-\mathrm{C}_{3} \mathrm{~N}_{4}$ with any other material can be reduced by following these mass ratios.
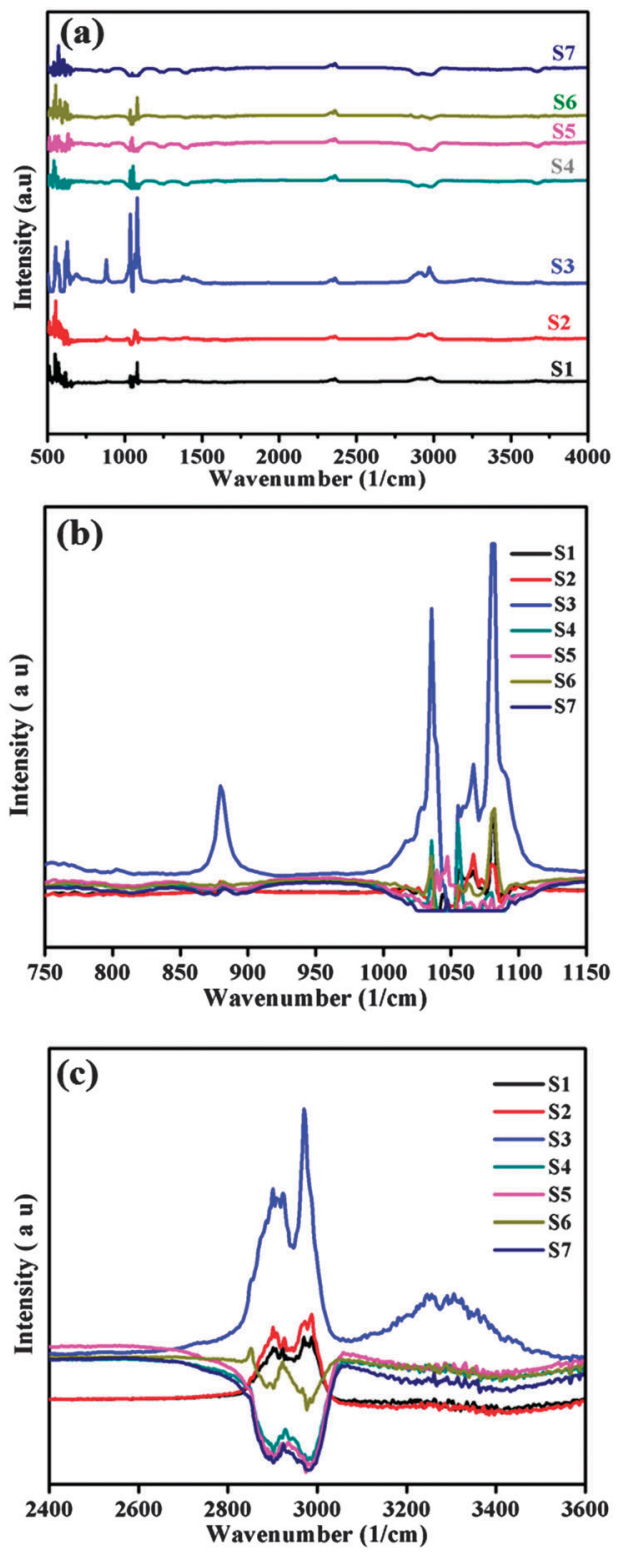

Fig. 4 (a) FTIR of all the samples (b and c) FTIR of all the samples in a short range.

It can be seen from the figure that if we increase the concentration of $\mathrm{g}-\mathrm{C}_{3} \mathrm{~N}_{4}$ from a specific value, the band gap of the samples again started to increase which can be noticed from the part of graph after 0.66 in Fig. $5(d)$.

The PL spectra of $\mathrm{WO}_{3}, \mathrm{~g}-\mathrm{C}_{3} \mathrm{~N}_{4}$ and all other samples were examined, as can be seen in Fig. 6(a-c). The excitation wavelength for PL spectra was set at $300 \mathrm{~nm}$. Both $\mathrm{g}-\mathrm{C}_{3} \mathrm{~N}_{4}$ and $\mathrm{WO}_{3}$ separately have peaks at around $460 \mathrm{~nm}$ which is due to their corresponding band gap. Fig. 6(c) shows the PL of all other samples. It can be seen that when $\mathrm{g}-\mathrm{C}_{3} \mathrm{~N}_{4}$ sheets were added to $\mathrm{WO}_{3}$ microrods, the emission intensity of the PL spectra for the $\mathrm{WO}_{3}-\mathrm{g}-\mathrm{C}_{3} \mathrm{~N}_{4}$ composite was decreased which indicates that the $\mathrm{WO}_{3}-\mathrm{g}-\mathrm{C}_{3} \mathrm{~N}_{4}$ had a much lower recombination rate of photogenerated charge carriers. The intensity of S5 is minimum whereas that of S3 is maximum, which shows that S5 has less 

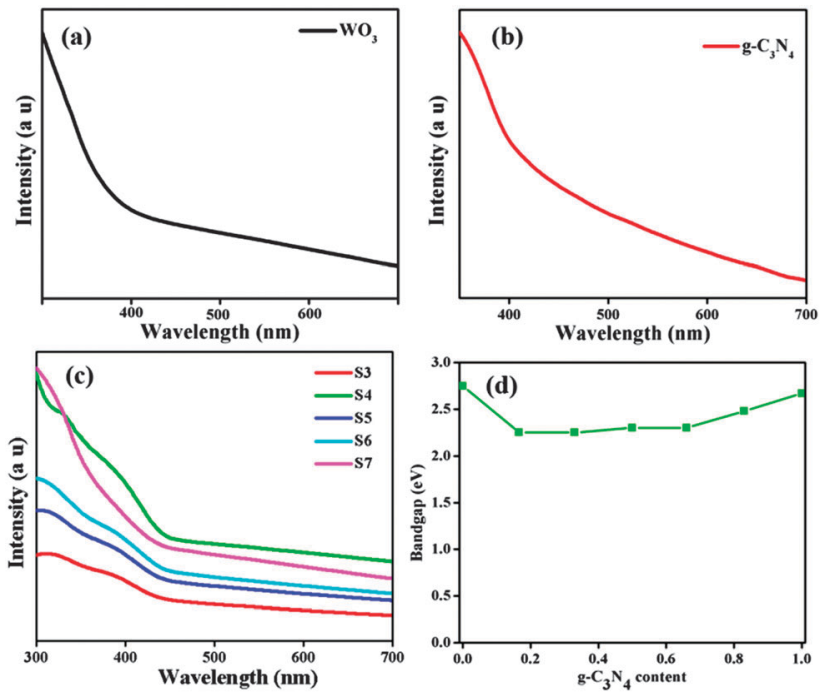

Fig. 5 (a) UV spectrum of $W_{3}$ (b) UV spectrum of $g-C_{3} N_{4}$ (c) UV spectra all the samples $(\mathrm{S} 3-\mathrm{S} 7)$ (d) band gap of all the samples with respect to the content ratio of $\mathrm{g}-\mathrm{C}_{3} \mathrm{~N}_{4}$.

crystal defects than all other samples. These crystal defects act as a recombination centre of holes and electrons.

\section{Evaluation of photocatalytic activity}

In order to investigate the photocatalytic property of the samples, photodegradation of RhB is performed. Fig. 7(a) shows how the main peak of $\mathrm{RhB}$ decreased with time. All the other samples are given in the ESI. $\dagger$ Pure $\mathrm{WO}_{3}$ takes 110 minutes while pure $g-\mathrm{C}_{3} \mathrm{~N}_{4}$ takes 80 minutes to completely degrade $\mathrm{RhB}$, whereas the sample S5 takes only 30 minutes for photodegradation of RhB as shown in Fig. 7(a). The photodegradation of all other samples is given in Fig. S2 (ESI $\dagger$ ).

Fig. 7(b) shows the $C / C_{0}$ of all the samples and one sample is without any catalyst. It shows the first order rate constant $k\left(\mathrm{~min}^{-1}\right)$ of $\mathrm{WO}_{3}(\mathrm{~S} 1), \mathrm{g}^{-} \mathrm{C}_{3} \mathrm{~N}_{4}(\mathrm{~S} 2)$ and composite samples (S3-S7), which was calculated by the following first order equation:

$$
\ln \left(C_{0} / C\right)=k t
$$

where $C_{0}$ is the initial concentration of the dye in solution and $C$ is the concentration of dye at time $t$. The sample without any catalyst shows no degradation throughout, which indicates that RhB is stable in water solution. Fig. 7(c) shows the $k$ values of all the samples. It can be seen that the $k$ value of S5 $\left(0.06912 \mathrm{~min}^{-1}\right)$ is highest compared to that of all other samples. The reason is that the addition of $\mathrm{g}-\mathrm{C}_{3} \mathrm{~N}_{4}$ into $\mathrm{WO}_{3}$ decreases the PL intensities of the composite samples as can be seen in Fig. 5(c). The decreased PL intensities indicate a slow recombination rate of photogenerated electron-hole pairs at the interface of composite samples which means that more number of electrons and holes take part in the oxidation and reduction reactions that results in the higher photocatalytic activity. ${ }^{58-60}$ As for the case of S5, the PL intensity is lowest which means that the recombination rate of photogenerated charge carries for S5 is much slower than all other samples. Therefore, S5 shows the highest activity. The $k$ values of pure
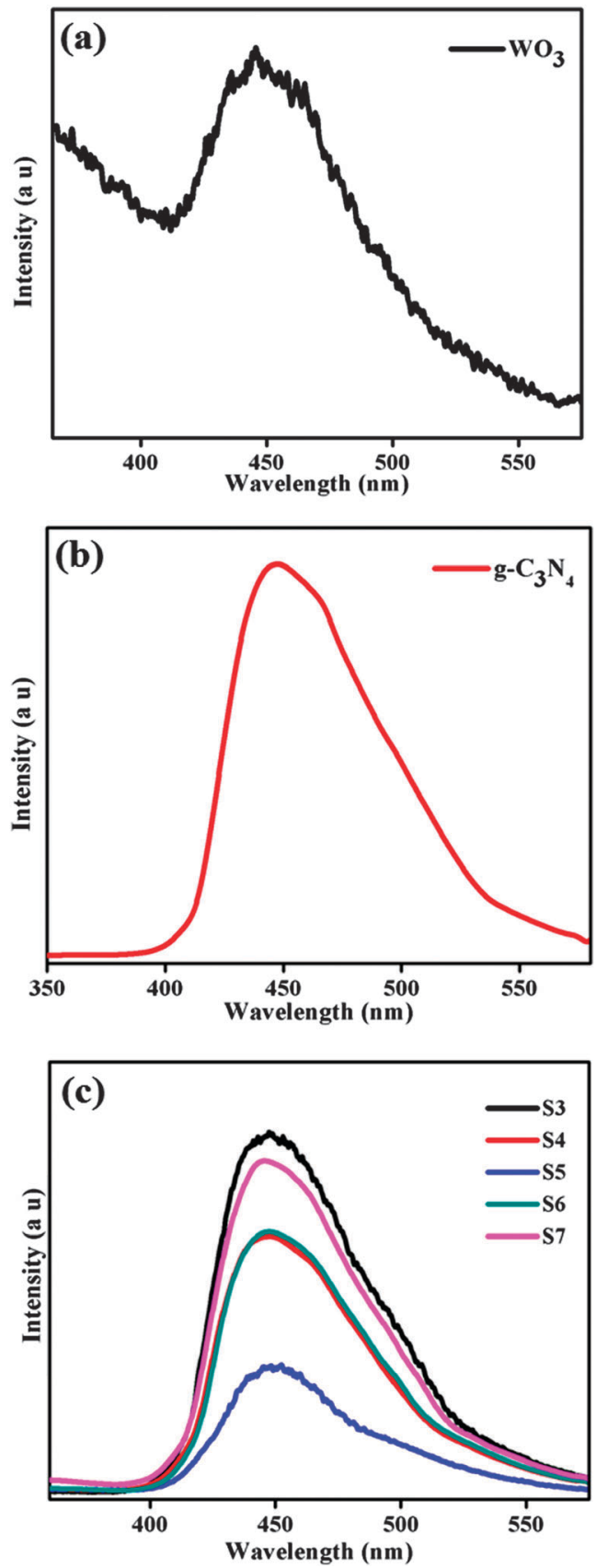

Fig. 6 (a) PL spectrum of $W_{3}$ (b) PL spectrum of $g-C_{3} N_{4}$ (c) PL spectra of all other samples.

$\mathrm{WO}_{3}\left(0.01893 \mathrm{~min}^{-1}\right)$ and $\mathrm{g}-\mathrm{C}_{3} \mathrm{~N}_{4}\left(0.01856 \mathrm{~min}^{-1}\right)$ are almost equal as clear from Fig. 7(c). When we increase the concentration of $\mathrm{g}-\mathrm{C}_{3} \mathrm{~N}_{4}$ in $\mathrm{WO}_{3}$, the $k$ value of the composites goes on increasing until the ratio of $\mathrm{g}-\mathrm{C}_{3} \mathrm{~N}_{4}$ and $\mathrm{WO}_{3}$ reaches $0.2: 1$. After this stage, the $k$ value of other samples is decreased which indicates that the ratio $(0.2: 1)$ for $\mathrm{S} 5$ was the best ratio for degrading RhB in visible light as observed from Fig. 7(c). Fig. 7(d) shows the reusability of the $\mathrm{S} 5$, as for practical application it is also necessary that the sample must be reusable and separate-able. After using thrice, the efficiency of the material is not much affected as can be seen in Fig. 7(d). 

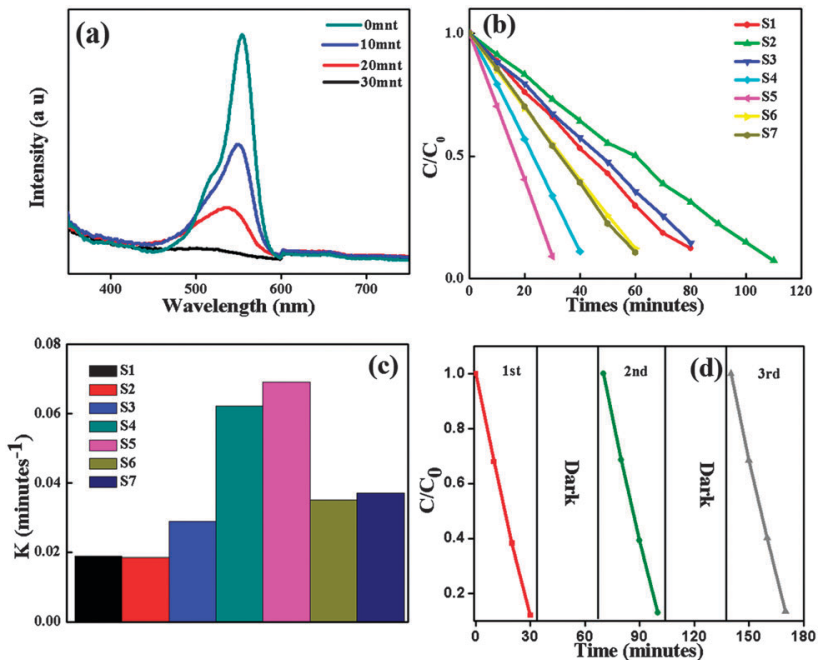

Fig. 7 (a) Photodegradation of RhB with $\mathrm{S} 5$ (b) $C / C_{0}$ of all the samples (S1-S7) (c) $k$ values of all the samples (S1-S7) (d) recyclability of S5.

\section{Proposed mechanism for the enhanced photocatalytic performance of $\mathrm{WO}_{3}-\mathrm{g}-\mathrm{C}_{3} \mathrm{~N}_{4}$}

Fig. 7 shows the results of RhB degradation under visible light irradiation in the presence of the synthesized composite $\mathrm{WO}_{3}-\mathrm{g}-\mathrm{C}_{3} \mathrm{~N}_{4}$ (S5). The excellent photodegradation of the organic dye on the surface of the $\mathrm{WO}_{3}-\mathrm{g}-\mathrm{C}_{3} \mathrm{~N}_{4}$ composite under the visible light occurred due to several factors. Firstly, there is a well-known factor that the heterostructured photocatalysts generally provide more reactive sites for catalysis and as well as for adsorption, so more organic pollutants are adsorbed that ultimately results in the fast photodegradation of the organic dye. Secondly, the very close contact of $\mathrm{WO}_{3}$ rods and $\mathrm{g}-\mathrm{C}_{3} \mathrm{~N}_{4}$ sheets with each other in the synthesized composite facilitates the transfer of photogenerated electron hole pairs from one semiconductor to other. Because the single crystal structured $\mathrm{WO}_{3}$ microrods provide a direct path for the transport of electrons to the composite surface unlike in a polycrystalline structure which is restricted by the grain boundaries. So, this easy transfer induces high separation of the photogenerated charge carriers and enhances the photocatalytic reaction rate. Fig. 8 shows the energy band structure diagram of the fabricated $\mathrm{WO}_{3}-\mathrm{g}-\mathrm{C}_{3} \mathrm{~N}_{4}$ composite-hybrid system. It can be noted from the figure that the transfer of photogenerated electrons takes place from the conduction band ( $\mathrm{CB}$ ) of $\mathrm{g}-\mathrm{C}_{3} \mathrm{~N}_{4}$ to the $\mathrm{CB}$ of $\mathrm{WO}_{3}$ and the photogenerated holes are transferred from the valence band (VB) of $\mathrm{WO}_{3}$ to the $\mathrm{VB}$ of $\mathrm{g}-\mathrm{C}_{3} \mathrm{~N}_{4}$. When the composite samples were exposed to a visible light source, electrons in the $\mathrm{VB}$ of $\mathrm{WO}_{3}$ and $\mathrm{g}-\mathrm{C}_{3} \mathrm{~N}_{4}$ were excited to $\mathrm{CB}$ of $\mathrm{WO}_{3}$ and $\mathrm{g}-\mathrm{C}_{3} \mathrm{~N}_{4}$ respectively. As a result, the holes were left in the $\mathrm{VB}$ of both materials, as can be seen in Fig. 8.

The valence and conduction band potentials of the pure $\mathrm{g}-\mathrm{C}_{3} \mathrm{~N}_{4}$ were found to be $1.57 \mathrm{eV}$ and $-1.12 \mathrm{eV},{ }^{61}$ whereas for pure $\mathrm{WO}_{3}$ their values were $3.18 \mathrm{eV}$ and $0.41 \mathrm{eV}$ respectively. ${ }^{62}$ As the $\mathrm{CB}$ potential of $\mathrm{g}-\mathrm{C}_{3} \mathrm{~N}_{4}(-1.12 \mathrm{eV})$ is lower than that of $\mathrm{WO}_{3}(0.41 \mathrm{eV})$, so the excited-state electrons from $\mathrm{CB}$ of $\mathrm{g}-\mathrm{C}_{3} \mathrm{~N}_{4}$ can directly transfer into the $\mathrm{CB}$ of $\mathrm{WO}_{3}$. On the other hand,

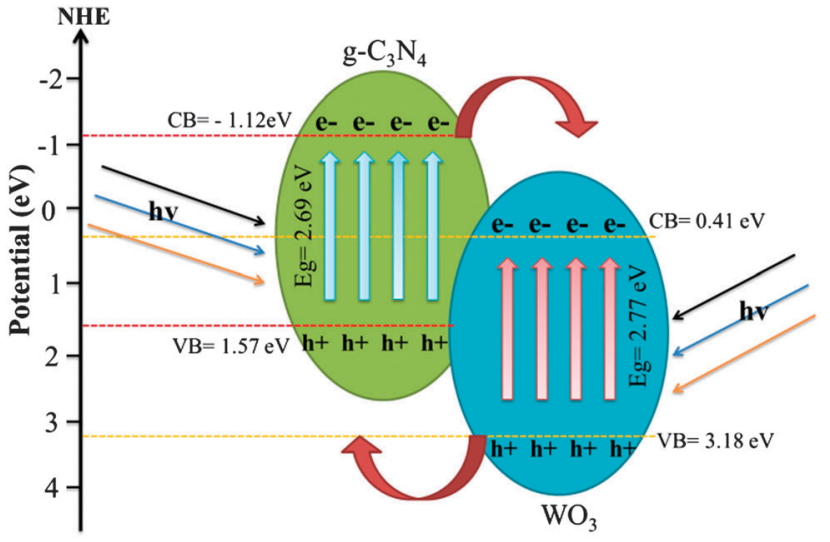

Fig. 8 Schematic illustration of the proposed mechanism for the photodegradation of $\mathrm{RhB}$ on the $\mathrm{WO}_{3}-\mathrm{g}-\mathrm{C}_{3} \mathrm{~N}_{4}$ composite.

the $\mathrm{VB}$ potential of $\mathrm{WO}_{3}(3.18 \mathrm{eV})$ is higher than that of $\mathrm{g}-\mathrm{C}_{3} \mathrm{~N}_{4}$ $(1.57 \mathrm{eV})$, so the photogenerated holes from the $\mathrm{VB}$ of $\mathrm{WO}_{3}$ can move to the $\mathrm{VB}$ of $\mathrm{g}-\mathrm{C}_{3} \mathrm{~N}_{4}$. The transfer of photo-induced electron hole pairs was accompanied by the consecutive reduction of $\mathrm{W}^{6+}$ into $\mathrm{W}^{5+}$ with the capture of photo-induced electrons at the trapping sites in $\mathrm{WO}_{3} \cdot{ }^{63}$ Simultaneously, the $\mathrm{W}^{5+}$ ions contained by the $\mathrm{WO}_{3}$ surface were re-oxidized into $\mathrm{W}^{6+}$ by the oxygen which was finally converted into $\mathrm{O}_{2}{ }^{-\bullet}$. This movement results in the efficient separation of photogenerated electron-hole pairs and a slow-down recombination rate which consequently promotes the photonic efficiency for the degradation of organic pollutants. As hydroxyl radicals $\left({ }^{\bullet} \mathrm{OH}\right)$ are well known strong oxidants, they can contribute to the degradation process of $\mathrm{RhB}$ in the presence of water vapor in air. The molecules of water further reacting with photogenerated holes $\left(\mathrm{h}^{+}\right)$or superoxide radicals $\left(\mathrm{O}_{2}{ }^{-\bullet}\right)$ at the photocatalyst surface can be converted to ${ }^{\bullet} \mathrm{OH}$ by the following reactions; ${ }^{64}$

$$
\begin{gathered}
\mathrm{h}^{+}+\mathrm{H}_{2} \mathrm{O} \rightarrow{ }^{\bullet} \mathrm{OH}+\mathrm{H}^{+} \\
2 \mathrm{O}_{2}^{-\bullet}+2 \mathrm{H}_{2} \mathrm{O} \rightarrow 2^{\bullet} \mathrm{OH}+2 \mathrm{OH}^{-}+\mathrm{O}_{2}
\end{gathered}
$$

The photogenerated holes were captured by hydroxyl groups $\left(\mathrm{OH}^{-}\right)$on the surface of the photocatalyst and produced hydroxyl radicals ${ }^{\bullet} \mathrm{OH} .{ }^{65}$ Similarly, hydrogen peroxide $\left(\mathrm{H}_{2} \mathrm{O}_{2}\right)$ is also a strong oxidant, the oxygen molecules react with photo-excited electrons at the surface of $\mathrm{WO}_{3}$ to be transformed into $\mathrm{H}_{2} \mathrm{O}_{2}$ through the following reaction; ${ }^{35}$

$$
\mathrm{O}_{2}+2 \mathrm{H}^{+}+2 \mathrm{e}^{-} \rightarrow \mathrm{H}_{2} \mathrm{O}_{2}
$$

The as-produced superoxide anions $\left(\mathrm{O}_{2}{ }^{-\bullet}\right)$ either directly react with $\mathrm{RhB}$ or produce the hydroxyl radicals $\left({ }^{\circ} \mathrm{OH}\right)$ by reacting with photo-induced electrons and hydrogen ions $\left(\mathrm{H}^{+}\right) .{ }^{66,67}$ The strong oxidants, hydroxyl radicals $\left({ }^{\bullet} \mathrm{OH}\right)$, finally degrade the organic pollutant RhB. In addition, the excellent separation of photogenerated electron-hole pairs can be verified from the PL spectra of the photocatalyst. It can be noted from Fig. 5(c) that the coupling of $\mathrm{g}-\mathrm{C}_{3} \mathrm{~N}_{4}$ with $\mathrm{WO}_{3}$ microrods had an obvious effect on the PL intensities of the composite samples; the PL intensities were dramatically decreased which is strong evidence of the slow 
recombination rate of photogenerated electron-hole pairs. As a result of this slow recombination the charge separation increases at the interface between two semiconductors, and the catalytic activity of $\mathrm{WO}_{3}-\mathrm{g}-\mathrm{C}_{3} \mathrm{~N}_{4}$ composites thus enhanced was much higher than that of bare $\mathrm{WO}_{3}$ and bare $\mathrm{g}-\mathrm{C}_{3} \mathrm{~N}_{4}$. The efficient separation of the charge carriers induced by the hybrid effect, the low energy optical absorption under visible light and enhanced adsorption were some of the factors for significant enhancement in the photocatalytic activity. However, it has been noted that the separation of photo-induced electron-hole pairs depends on the suitable band-edge positions of the two semiconductors, because the band structure of the photocatalyst plays an important role in the separation process of the electron-hole pairs. ${ }^{68,69}$ The suitable band structure alignment of such semiconductors is favourable for charge accumulation/depletion at the interfaces which induces the separation of photo-induced electrons and holes ${ }^{70}$ and as a result their photocatalytic efficiency is enhanced. We anticipate that the fabricated composite may also be useful for the hydrogen production via water splitting due to its favourable band gap, less recombination rate of electron-hole pairs and less number of crystal defects.

\section{Conclusions}

We have successfully prepared a novel $\mathrm{WO}_{3}-\mathrm{g}-\mathrm{C}_{3} \mathrm{~N}_{4}$ visible-lightdriven photocatalyst and used it for the photodegradation of rhodamine $\mathrm{B}$. The sample $\mathrm{S} 5$ of the as-prepared $\mathrm{WO}_{3}-\mathrm{g}-\mathrm{C}_{3} \mathrm{~N}_{4}$ photocatalyst showed the highest photocatalytic efficiency. It has been noted that the as-synthesized $\mathrm{WO}_{3}-\mathrm{g}-\mathrm{C}_{3} \mathrm{~N}_{4}$ composite (S5) exhibited performance 3.6 and 3.7 times as high as those of bare $\mathrm{WO}_{3}$ and $\mathrm{g}-\mathrm{C}_{3} \mathrm{~N}_{4}$ under visible light irradiation respectively. The enhancement in the photocatalytic activity occurs by coupling g- $\mathrm{C}_{3} \mathrm{~N}_{4}$ with $\mathrm{WO}_{3}$ and is mainly due to following factors: (i) the synergistic effect between $\mathrm{WO}_{3}$ and $\mathrm{g}-\mathrm{C}_{3} \mathrm{~N}_{4}$, (ii) high separation and easy transfer of photo-induced electron-hole pairs at the interface of the composite, and (iii) the lower number of defects. The composite $\left(\mathrm{WO}_{3}-\mathrm{g}-\mathrm{C}_{3} \mathrm{~N}_{4}\right)$ can be easily synthesized by a simple physical mixing and annealing method and it can exhibit efficient photocatalytic performance in a variety of environments, particularly under visible (fluorescent) light. Moreover, it can be a good reference to develop more superior photocatalysts with high potential for using cheap solar light to solve the energy and environmental problems.

\section{Acknowledgements}

This work was supported by National Natural Science Foundation of China (23171023, 50972017) and the Research Fund for the Doctoral Program of Higher Education of China (20101101110026).

\section{Notes and references}

1 M. R. Hoffmann, S. T. Martin, W. Choi and D. W. Bahnemann, Chem. Rev., 1995, 95, 69.

2 (a) H. Choi, A. C. Sofranko and D. D. Dionysiou, Adv. Funct. Mater., 2006, 16, 1067; (b) M. Tanveer, C. Cao, I. Aslam, Z. Ali,
F. Idrees, W. S. Khan, F. K. Butt, M. Tahir and A. Mahmood, Sci. Adv. Mater., 2014, DOI: 10.1166/sam.2014.1988.

3 (a) F. Idrees, C. Cao, F. K. Butt, M. Tahir, M. Tanveer, I. Aslam, Z. Ali, T. Mahmood and J. Hou, CrystEngComm, 2013, 15, 8146; (b) F. Idrees, C. Cao, R. Ahmed, F. K. Butt, S. Butt, M. Tahir, M. Tanvir, I. Aslam and Z. Ali, Sci. Adv. Mater., 2014, DOI: 10.1166/sam.2014.2044.

4 A. Fujishima and K. Honda, Nature, 1972, 238, 37.

5 (a) S. Zheng, W. Jiang, Y. Cai, D. D. Dionysiou and K. E. O'Sheab, Catal. Today, 2014, 224, 88; (b) F. K. Butt, M. Tahir, C. Cao, F. Idrees, R. Ahmed, W. S. Khan, Z. Ali, N. Mahmood, M. Tanveer, A. Mahmood and I. Aslam, ACS Appl. Mater. Interfaces, 2014, 6, 13635.

6 W. Jiang, J. A. Joens, D. D. Dionysiou and K. E. O'Shea, J. Photochem. Photobiol., A, 2013, 262, 13.

7 (a) A. L. Linsebigler, G. Lu and J. T. Yates, Chem. Rev., 1995, 95, 735; (b) M. Tanveer, C. Cao, Z. Ali, I. Aslam, F. Idrees, W. S. Khan, F. K. But, M. Tahir and N. Mahmood, CrystEngComm, 2014, 16, 5290.

8 X. Chen and S. S. Mao, Chem. Rev., 2007, 10, 2891.

9 Z. G. Zhao and M. Miyauchi, Angew. Chem., Int. Ed., 2008, 47, 7051.

10 R. Liu, Y. Yin, L. Y. Chou, S. W. Sheehan, W. He, F. Zhang, H. J. Hou and D. Wang, Angew. Chem., Int. Ed., 2011, 50, 499.

11 S. Wang, X. Feng, J. Yao and L. Jiang, Angew. Chem., Int. Ed., 2006, 45, 1264.

12 B. Zhang, C. Cao, H. Qiu, Y. Xu, Y. Wang and H. Zhu, Chem. Lett., 2005, 34, 154.

13 (a) I. Aslam, C. Cao, W. S. Khan, M. Tanveer, M. Abid, F. Idrees, R. Riasat, M. Tahir, F. K. Butt and Z. Ali, RSC Adv., 2014, 4, 37914; (b) M. Kang, C. Cao, X. Xu and B. Liao, Chin. Sci. Bull., 2008, 53, 335.

14 D. Bi and Y. Xu, Langmuir, 2011, 27, 9359.

15 C. Li, C. Cao and H. Zhu, Chin. Sci. Bull., 2003, 48, 1737.

16 J. Li, C. Cao and H. Zhu, Nanotechnology, 2007, 18, 115605.

17 F. Huang, C. Cao, X. Xiang, R. Lv and H. Zhu, Diamond Relat. Mater., 2004, 13, 1757.

18 X. Wang, K. Maeda, X. Chen, K. Takanabe, K. Domen, Y. Hou, X. Fu and M. Antonietti, J. Am. Chem. Soc., 2009, 131, 1680.

19 (a) M. Tahir, C. Cao, F. K. Butt, F. Idrees, N. Mahmood, Z. Ali, I. Aslam, M. Tanveer, M. Rizwan and T. Mahmood, J. Mater. Chem. A, 2013, 1, 13949; (b) M. Tahir, C. Cao, F. K. Butt, S. Butt, F. Idrees, Z. Ali, I. Aslam, M. Tanveer, A. Mahmood and N. Mahmood, CrystEngComm, 2014, 16, 1825.

20 (a) J. D. Hong, X. Y. Xia, Y. S. Wang and R. Xu, J. Mater. Chem., 2012, 22, 15006; (b) M. Tahir, C. Cao, N. Mahmood, F. K. Butt, A. Mahmood, F. Idrees, S. Hussain, M. Tanveer, Z. Ali and I. Aslam, ACS Appl. Mater. Interfaces, 2014, 6, 1258. 21 S. Yang, Y. Gong, J. Zhang, L. Zhan, L. Ma, Z. Fang, R. Vajtai, X. Wang and P. M. Ajayan, Adv. Mater., 2013, 25, 2452.

22 P. Niu, L. L. Zhang, G. Liu and H. M. Cheng, Adv. Funct. Mater., 2012, 22, 4763.

23 L. Huang, H. Xu, R. Zhang, X. Cheng, J. Xia, Y. Xu and H. Li, Appl. Surf. Sci., 2013, 283, 25. 
24 M. Law, L. E. Greene, J. C. Johnson, R. Saykally and P. D. Yang, Nat. Mater., 2005, 4, 455.

25 F. Qian, G. M. Wang and Y. Li, Nano Lett., 2010, 10, 4686.

26 G. M. Wang, X. Y. Yang, F. Qian, J. Z. Zhang and Y. Li, Nano Lett., 2010, 10, 1088.

27 J. Cao, B. Xu, B. Luo, H. Lin and S. Chen, Catal. Commun., 2011, 13, 63.

28 L. Zhang, K. H. Wonga, Z. Chen, J. C. Yu, J. Zhao, C. Hu, C. Y. Chan and P. K. Wong, Appl. Catal., A, 2009, 363, 221.

29 J. Jiang, X. Zhang, P. B. Sun and L. Z. Zhang, J. Phys. Chem. C, 2011, 115, 20564.

30 Y. Y. Wen, H. M. Ding and Y. K. Shan, Nanoscale, 2011, 3, 4417.

31 K. H. Reddy, S. Martha and K. M. Parida, Inorg. Chem., 2013, 52, 6401.

32 J. J. Guo, S. X. Ouyang, P. Li, Y. J. Zhang, T. Kako and J. H. Ye, Appl. Catal., B, 2013, 134-135, 292.

33 W. Morales, M. Cason, O. Aina, N. R. de Tacconi and K. Rajeshwar, J. Am. Chem. Soc., 2008, 130, 6319.

34 D. Hidayat, A. Purwanto, W. N. Wang and K. Okuyama, Mater. Res. Bull., 2010, 45, 173.

35 R. Abe, H. Takami, N. Murakami and B. Ohtani, J. Am. Chem. Soc., 2008, 130, 7781.

36 M. Qamar, M. A. Gondal and Z. H. Yamani, Catal. Commun., 2010, 11, 772.

37 S. A. K. Leghari, S. Sajjad, F. Chen and J. Zhang, Chem. Eng. J., 2011, 166, 915.

38 H. Widiyandari, A. Purwanto, R. Balgis, T. Ogi and K. Okuyama, Chem. Eng. J., 2012, 180, 329.

39 T. Arai, M. Yanagida, Y. Konishi, Y. Iwasaki, H. Sugihara and K. Sayama, J. Phys. Chem. C, 2007, 111, 7577.

40 Z. F. Liu, Z. G. Zhao and M. Miyauchi, J. Phys. Chem. C, 2009, 113, 17132.

41 S. Yan, S. Lv, Z. Li and Z. Zou, Dalton Trans., 2010, 39, 1488.

42 C. Pan, J. Xu, Y. Wang, D. Li and Y. Zhu, Adv. Funct. Mater., 2012, 22, 1518.

43 L. Huang, H. Xu, Y. Li, H. Li, X. Cheng, J. Xia, Y. Xua and G. Cai, Dalton Trans., 2013, 42, 8606.

44 Y. Zang, L. Li, Y. Zuo, H. Lin, G. Li and X. Gua, $R S C A d v$., 2013, 3, 13646.

45 K. Katsumata, R. Motoyoshi, N. Matsushita and K. Okada, J. Hazard. Mater., 2013, 260, 475.

46 Y. Wang, R. Shi, J. Lin and Y. Zhu, Energy Environ. Sci., 2011, 4, 2922.
47 C. Guéry, C. Choquet, F. Dujeancourt, J. M. Tarascon and J. C. Lassègues, J. Solid State Electrochem., 1997, 1, 199.

48 V. N. Khabashesku, J. L. Zimmerman and J. L. Margrave, Chem. Mater., 2000, 12, 3264.

49 X. Li, J. Zhang, L. Shen, Y. Ma, W. Lei, Q. Cui and G. Zou, Appl. Phys. A: Mater. Sci. Process., 2009, 94, 387.

50 S. C. Yan, Z. S. Li and Z. G. Zou, Langmuir, 2009, 25, 10397.

51 M. J. Bojdys, J. O. Müller, M. Antonietti and A. Thomas, Chem. - Eur. J., 2008, 14, 8177.

52 M. Yang, Q. Huang and X. Jin, Mater. Sci. Eng., B, 2012, 177, 600 .

53 S. C. Yan, Z. S. Li and Z. G. Zou, Langmuir, 2009, 25, 10397.

54 J. Fu, Y. L. Tian, B. B. Chang, F. N. Xi and X. P. Dong, J. Mater. Chem., 2012, 22, 21159.

55 M. J. Bojdys, J. O. Muller, M. Antonietti and A. Thomas, Chem. - Eur. J., 2008, 14, 8177.

56 S. Kumar, T. Surendar, A. Baruah and V. Shanker, J. Mater. Chem. A, 2013, 1, 5333.

57 H. I. S. Nogueira, A. M. V. Cavaleiro, J. Rocha, T. Trindade and J. D. P. D. Jesus, Mater. Res. Bull., 2004, 39, 683.

58 Y. Yang, G. Zhang, S. Yu and X. Shen, Chem. Eng. J., 2010, $162,171$.

59 S. F. Chen, W. Zhao, W. Liu, H. Y. Zhang and X. L. Yu, J. Hazard. Mater., 2009, 172, 1415.

60 H. Huang, D. Li, Q. Lin, W. Zhang, Y. Shao, Y. Chen, M. Sun and X. Fu, Environ. Sci. Technol., 2009, 43, 4164.

61 L. Ge, C. C. Han and J. Liu, Appl. Catal., B, 2011, 108, 100.

62 S. J. Hong, S. Lee, J. S. Jang and J. S. Lee, Energy Environ. Sci., 2011, 4, 1781.

63 V. Keller, P. Bernhardt and F. Garin, J. Catal., 2003, 215, 129.

64 G. Vincent, P. M. Marquaire and O. Zahraa, J. Hazard. Mater., 2009, 161, 1173.

65 N. Zhang, S. Q. Liu, X. Z. Fu and Y. J. Xu, J. Phys. Chem. C, 2011, 115, 9136.

66 L. R. Zheng, Y. H. Zheng, C. Q. Chen, Y. Y. Zhan, X. Y. Lin, Q. Zheng, K. M. Wei and J. F. Zhu, Inorg. Chem., 2009, 48, 1819.

67 O. Legrini, E. Oliveros and A. M. Braun, Chem. Rev., 1993, 93, 671 .

68 J. Tersoff, Phys. Rev. B: Condens. Matter Mater. Phys., 1984, 30, 4874.

69 Z. Alferov, Semiconductors, 1998, 32, 1.

70 J. Zhang, M. Zhang, R. Q. Sun and X. Wang, Angew. Chem., Int. Ed., 2012, 51, 10145. 